\title{
Primary Care Utilization and Expenditures in Traditional Medicare and Medicare Advantage, 2007-2016
}

J Gen Intern Med 35(8):2480-1

DOI: $10.1007 / \mathrm{s} 11606-020-05826-\mathrm{x}$

(c) Society of General Internal Medicine 2020

\section{INTRODUCTION}

Achieving effective, high-quality primary care for Medicare beneficiaries is a national priority as it encourages health promotion and maintenance, potentially reducing intensity of acute care services. ${ }^{1}$ Currently, there is ample data documenting intensity of primary care services, including rates of utilization and expenditures, for beneficiaries in feefor-service Traditional Medicare (TM). ${ }^{2,}{ }^{3}$ However, less is known about the beneficiaries enrolled in Medicare Advantage (MA) plans, which now include $33 \%$ of the Medicare population. ${ }^{4}$ As managed care's goal is to control costs while maintaining a high quality, MA plans may encourage greater primary care than is the case in TM. We examined whether this is the case by assessing primary care utilization and expenditures among beneficiaries in MA and TM.

\section{METHODS}

Our analysis uses the Medical Expenditure Panel Survey (MEPS) data from 2007 to 2016. MEPS is a nationally representative survey of the US civilian, non-institutionalized population. Specifically, we use the full-year consolidated data, the outpatient visit, and the office-based medical provider visit files within MEPS. We included Medicare beneficiaries 65 years or older enrolled in TM or MA plans during all three waves of data collection for each year. We excluded those who died and dual Medicare/Medicaid beneficiaries. The unit of our analysis is at the annual individual level. Our study was exempt from institutional review board approval.

Our primary outcomes were the number of primary care visits during the year and annual primary care expenditures (adjusted to 2018 US dollars). We defined primary care services as visits to family medicine, internal medicine, pediatric medicine, and general practice providers. ${ }^{2}$ We also included utilization of preventive services recommended by the United States Preventive Services Task Force (routine checkup within the past year, blood pressure checkup within the past 2 years, cholesterol check within the past 5 years, and flu vaccination within the past year) as a secondary outcome.

Received August 5, 2019

Accepted March 27, 2020

Published online May 6, 2020
Our key independent variable was MA enrollment. We included demographic, socioeconomic, and health status variables as control variables.

To account for differences between TM and MA beneficiaries attributable to selection bias, we computed the inverse probability of treatment weighting (IPTW) as a propensity for being an MA beneficiary based on control variables. We then examined the difference in outcomes among MA beneficiaries relative to TM beneficiaries using a linear regression model or a logistic regression model after applying the IPTW. We also examined the difference without accounting for the IPTW. We used survey weights to adjust sample characteristics to be representative of the Medicare population. ${ }^{5}$

\section{RESULTS}

After imposing inclusion and exclusion criteria, $7916 \mathrm{TM}$ beneficiaries and 3879 MA beneficiaries met study criteria (Table 1). There were small differences in weighted sample characteristics between TM and MA beneficiaries and these differences further decreased after applying IPTW (not shown). Our IPTW-adjusted analyses showed that relative to TM beneficiaries, MA beneficiaries had 0.15 (95\% CI 0.01, 0.29 ) more primary care visits per person, but they had $\$ 59$ $(95 \%$ CI $-106,-11)$ lower primary care expenditures per person (Table 2), which is equivalent to $5.40 \%$ and $10.95 \%$ of the corresponding unadjusted estimates for TM beneficiaries. Compared to TM beneficiaries, MA beneficiaries had a relatively higher likelihood of having all preventive services with an exception for cholesterol checkups (1.29 [95\% CI $1.09,1.53$ ] 1.64 [95\% CI 1.10, 2.43], 1.15 [95\% CI 1.02,

Table 1 Primary Care Utilization and Expenditures Between Traditional Medicare and Medicare Advantage Beneficiaries

\begin{tabular}{lll}
\hline \hline & $\begin{array}{l}\text { TM beneficiaries } \\
(\mathbf{N = 7 9 1 6 )}\end{array}$ & $\begin{array}{l}\text { MA beneficiaries } \\
(\boldsymbol{N}=\mathbf{3 8 7 9})\end{array}$ \\
\hline $\begin{array}{l}\text { Number of primary care } \\
\text { visits per year, mean (SD) }\end{array}$ & $2.78(3.01)$ & $2.89(3.13)$ \\
$\begin{array}{l}\text { Annual primary care } \\
\text { expenditures, mean (SD) }\end{array}$ & $539(1344)$ & $476(811)$ \\
$\begin{array}{l}\text { Routine checkup within } \\
\text { the past year, } N(\%)\end{array}$ & $7032(88.83)$ & $3537(91.18)$ \\
$\begin{array}{l}\text { Blood pressure check } \\
\text { within the past 2 years, } N \\
(\%)\end{array}$ & $7750(97.90)$ & $3825(98.61)$ \\
$\begin{array}{l}\text { Cholesterol check within } \\
\text { the past 5 years, } N(\%)\end{array}$ & $7705(97.33)$ & $3815(98.35)$ \\
$\begin{array}{l}\text { Flu vaccination within the } \\
\text { past year, } N(\%)\end{array}$ & $5739(72.50)$ & $2821(72.72)$ \\
\hline
\end{tabular}

TM traditional Medicare, MA Medicare Advantage 
Table 2 Primary Care Utilization and Expenditures Between Traditional Medicare and Medicare Advantage Beneficiaries After Inverse Probability of Treatment Weighting

\begin{tabular}{|c|c|c|c|c|}
\hline & \multicolumn{4}{|c|}{$\begin{array}{l}\text { Differences among MA beneficiaries relative to TM beneficiaries, coefficient, or OR } \\
(95 \% \mathrm{CI})^{*}\end{array}$} \\
\hline & Without IPTW & $P$ value & With IPTW & $P$ value \\
\hline $\begin{array}{l}\text { Number of primary care visits per year } \\
\text { Annual primary care expenditures } \\
\text { Routine checkup within the past year } \\
\text { Blood pressure check within the past } 2 \text { years } \\
\text { Cholesterol check within the past } 5 \text { years } \\
\text { Flu vaccination within the past year }\end{array}$ & $\begin{array}{l}0.15(0.01 \text { to } 0.29) \\
-57(-106 \text { to }-9) \\
1.30(1.10 \text { to } 1.54) \\
1.66(1.09 \text { to } 2.52) \\
1.56(1.06 \text { to } 2.30) \\
1.14(1.03 \text { to } 1.28)\end{array}$ & $\begin{array}{l}0.04 \\
0.02 \\
0.00 \\
0.01 \\
0.02 \\
0.01\end{array}$ & $\begin{array}{l}0.15(0.01 \text { to } 0.29) \\
-59(-106 \text { to }-11) \\
1.29(1.09 \text { to } 1.53) \\
1.64(1.10 \text { to } 2.43) \\
1.45(0.99 \text { to } 2.15) \\
1.15(1.02 \text { to } 1.28)\end{array}$ & $\begin{array}{l}0.03 \\
0.01 \\
0.00 \\
0.01 \\
0.05 \\
0.01\end{array}$ \\
\hline
\end{tabular}

*The inverse probability of treatment weighting (IPTW) was computed as a propensity for being an MA beneficiary based on observable characteristics (age, sex, marital status, racelethnicity, education, family income, area of residence, self-reported health status, interference of normal work due to pain, limited moderated activities due to health, interference of social activities due to physical health or emotional problems, whether felt calm and peaceful, whether felt downhearted and blue, whether had a lots of energy, any limitation at work or house, functional limitation, cognitive limitation, physical health summary scores, mental health summary scores, current smoking status, and 12 chronic conditions) and then adjusted estimates were derived using a linear regression model or a logistic regression model after applying the IPTW. Survey weights were used to adjust sample characteristics to be representative of the Medicare population

${ }^{7}$ The estimate represents a coefficient from a linear regression model

${ }^{*}$ The estimate represents an odds ratio from a logistic regression model

IPTW inverse probability of treatment weights, TM traditional Medicare, MA Medicare Advantage

1.28] for routine checkup, blood pressure checkup, and flu vaccination, respectively).

\section{DISCUSSION}

Compared to TM beneficiaries, MA beneficiaries had significantly higher rates of primary care visits and lower costs for these services, but the differences were not substantial. Furthermore, MA beneficiaries were more likely to receive essential preventive services compared to TM beneficiaries. Our findings suggest that MA beneficiaries not only have more primary care but also receive primary care at lower prices. The prices are relatively low, and thus this may offset the difference in primary care utilization.

The study has several limitations. First, as our definition of primary care may be narrow, we may exclude some primary care services. Second, we could not completely address selection bias because we did not account for unobservable characteristics between TM and MA beneficiaries.

Sungchul Park, $\mathrm{PhD} M P H$

Department of Health Management and Policy, Dornsife

School of Public Health, Drexel University,

Philadelphia, PA, USA

Jose F. Figueroa, MD MPH

Department of Health Policy and Management,

Harvard T.H. Chan School of Public Health,

Boston, MA, USA

Jose F. Figueroa, MD MPH

Department of Medicine, Brigham and Women's Hospital,

Boston, MA, USA

Paul Fishman, $P h D$

Department of Health Services, School of Public Health,

University of Washington,

Seattle, WA, USA
Norma B. Coe, PhD

Department of Medical Ethics and Health Policy, Perelman School of Medicine, University of Pennsylvania, Philadelphia, PA, USA

Corresponding Author: Sungchul Park, PhD MPH; Department of Health Management and Policy, Dornsife School of Public Health, Drexel University Philadelphia, PA, USA

(e-mail: smp462@drexel.edu).

\section{Compliance with Ethical Standards:}

Conflict of Interest: The authors declare that they do not have a conflict of interest.

\section{REFERENCES}

1. Friedberg MW, Hussey PS, Schneider EC. Primary care: a critical review of the evidence on quality and costs of health care. Health Aff (Millwood). 2010;29(5):766-772.

2. Reid R, Damberg C, Friedberg MW. Primary care spending in the fee-forservice Medicare population. JAMA Intern Med. 2019.

3. Gold M, Casillas G. What do we know about health care access and quality in Medicare Advantage versus the traditional Medicare program? Washington, DC: Kaiser Family Foundation, November 2014 (https:// www.kff.org/medicare/report/what-do-we-know-about-health-care-access-and-quality-in-medicare-advantage-versus-the-traditional-medicareprogram/).

4. Neuman P, Jacobson GA. Medicare Advantage checkup. N Engl J Med. 2018;379(22):2163-2172.

5. DuGoff EH, Schuler M, Stuart EA. Generalizing observational study results: applying propensity score methods to complex surveys. Health Serv Res. 2014;49(1):284-303.

Publisher's Note: Springer Nature remains neutral with regard to jurisdictional claims in published maps and institutional affiliations. 